\title{
Suicidal Thought and Associated Factors Among Patients with Diabetes Mellitus at North-west Ethiopia: Unemployment and Depression Matters
}

\author{
Mogesie Necho ${ }^{1, ~ *}$, Mengesha Birkie ${ }^{1}$, Asmare Belete ${ }^{1}$, Merid Abadisharew ${ }^{2}$ \\ ${ }^{1}$ Department of Psychiatry, College of Medicine and Health Sciences, Wollo University, Dessie, Ethiopia \\ ${ }^{2}$ Department of Sociology, College of Social Science and Humanity, Wollo University, Dessie, Ethiopia
}

Email address:

nechomoges2014@gmail.com (M. Necho), mengeshasun@gmail.com (M. Birkie), yasmarebel@yahoo.com (A. Belete), meridabadisharew@gmail.com (M. Abadisharew)

${ }^{*}$ Corresponding author

\section{To cite this article:}

Mogesie Necho Alebachew, Mengesha Birkie, Asmare Belete, Merid Abadisharew. Suicidal Thought and Associated Factors Among Patients with Diabetes Mellitus at North-west Ethiopia: Unemployment and Depression Matters. American Journal of Psychiatry and Neuroscience. Vol. 8, No. 4, 2020, pp. 78-86. doi: 10.11648/j.ajpn.20200804.13

Received: September 30, 2020; Accepted: October 22, 2020; Published: November 27, 2020

\begin{abstract}
Background: Suicidal thought precedes other suicidal behaviors and is associated with the risk of attempting and committing suicide. However, the issue is not well studied in developing countries in general and Ethiopia in particular. Therefore, this study is conducted to assess 'lifetime prevalence and factors affecting suicidal thoughts among diabetes mellitus patients at Felegehiwot referral hospital. Method: we conducted analytic cross-sectional study from May 21 to June 21 at diabetic follow-up clinic. A systematic random sampling technique was applied to recruit a total of 421 participants. The suicide manual of the composite international diagnostic interview was adapted to assess suicidal thoughts. The medical chart of patients was reviewed to obtain relevant data on clinical variables. The factors associated with suicidal thoughts were identified with the binary logistic regression method. The strength of association between independent variables and suicidal thought was measured with odds ratio with $95 \% \mathrm{CI}$ and the p-value of $<0.05$ in multivariable logistic regression were considered statistically significant. Results: A total of 421 participants were interviewed. The lifetime prevalence of Suicidal thoughts was found to be $19.7 \%$. Being divorced/widowed ( $\mathrm{AOR}=2.38,95 \% \mathrm{CI}: 1.12,5.02$ ), unemployment ( $\mathrm{AOR}=3.67,95 \%$ CI: $1.19,11.32$ ), type 1 diabetes ( $\mathrm{AOR}=2.56,95 \%$ CI: $1.16,5.73$ ), comorbidity of medical illness (AOR $=4.74,95 \%$ CI: 2.26 , 9.93), and comorbid depression ( $\mathrm{AOR}=1.92,95 \% \mathrm{CI}$ : $1.09,3.38$ ) were associated with suicidal thought. Conclusions: Suicidal thought was found to be an important public health problem in diabetes mellitus patients. So, early identification and treatment of patients with suicidal thoughts are important. Moreover; the management of medical comorbidities, depression, and psychosocial problems should be given due consideration.
\end{abstract}

Keywords: Suicidal Thought, Diabetes Mellitus, Ethiopia

\section{Background}

World Health Organization (WHO) estimates that almost one million people die of suicide every year and 10 to 20 times more people attempt suicide worldwide [1]. Among adults of 15-29 years, suicide accounts for $8.5 \%$ of all deaths and ranked as the 2nd leading cause of death next to traffic accidents [2]. Despite, decades of scientific efforts to improve methods of predicting and preventing suicide [3], suicidal behaviors have greatly increased globally [4].
Internationally, suicide rates range from highs of more than 25 per 100,000 persons in Lithuania, South Korea, Sri Lanka, and Guyana to fewer than 10 per 100,000 in Portugal, the Netherlands, Spain, South Africa, Egypt [5].

Suicide ideation (SI) is defined as thinking about; planning one's death and is associated with an increased risk of attempting and committing suicide [4]. International reports show that SI prevalence among the general population ranges from $2.1 \%$ to $6.8 \%$ worldwide, and is variable, depending on socio-demographic factors, such as age, sex, marital status, 
occupation, and social support [6-9]. Moreover; approximately, 90 percent of suicide cases fulfill criteria for a psychiatric disorder, particularly major depressive disorder, substance use disorders, and schizophrenia [10-17].

Chronic medical illness imposes unexplained pains, increased utilization of healthcare resources, anxiety, and depressive feelings on patients, all of which delay recovery and healing process [18]. The prevalence of depression and psychiatric diseases among adults with Type 1 diabetes mellitus or Type 2 diabetes mellitus is approximately double that observed in the general population $[19,20]$. Depression harms self-care [21] and related to poorer glycemic outcomes and therefore increased the risk of complication.

An institution-based cross-sectional study conducted in wake forest university hospital, the United States of America (USA) on 91 Type 1 diabetes mellitus adolescents attending follow up visit showed that lifetime suicidal thought was 26.4\% [22]. Another cross-sectional study conducted in Korea adults older than 20 years of age with both diabetes and depression by taking 17,065 subjects reported that $51.4 \%$ of participants had a suicidal thought in their lifetime. Other studies revealed that the prevalence of suicidal thoughts was $58.5 \%$ and $9 \%$ in the United States of America studies [23, 24], 20\% in Jordan [8], 15\% in Canada [25], and 14\% in Australia [26].

A multitude of factors may also contribute to suicidal thoughts among patients with diabetes mellitus, such as unemployment, chronicity of illness, non-adherence to medication, poor glycemic control, depression, substance abuse problems, and family history of suicidal behavior [22, 27, 28]. This emphasizes the role of socio-demographic and clinical factors when assessing SI among patients diagnosed with diabetes mellitus.

However, little is known about suicidal thought and associated factors in diabetic patients in Ethiopia and this study aimed to assess the prevalence and determining factors of suicidal thoughts among people on follow up for diabetes mellitus, northwest Ethiopia, 2017.

\section{Methods}

\subsection{Study Design and Period}

The design of the study was an institution based analytical cross-sectional and the study was conducted from May 21 to June 21, 2017.

\subsection{Study Setting}

This study was conducted at a diabetic follow up clinic of Felegehiwot Referral Hospital which is found in Bahir Dar; the Capital City of Amhara Region, $565 \mathrm{~km}$ away from Addis Ababa the Capital City of Ethiopia in the northwest direction. More than 5.5 million people are getting service in the catchment area of the hospital [29].

\subsection{Source Population}

The source population for the study was diabetes patients attending follow up treatment at the Diabetes outpatient clinic of Felegehiwot Referral Hospital.

\subsection{Study Population}

Diabetic patients who attended follow up at the clinic during the data collection period. Inclusion Criteria

Diabetic Mellitus patients aged 18 years and older who have been on follow up treatment for DM were recruited into the study.

\subsection{Exclusion Criteria}

Patients seriously ill and unable to communicate were not given the chance to be included.

\subsection{Sample Size Determination and Sampling Technique}

The sample size required for the study was 423 which was determined using single population proportion formula, assuming an estimated prevalence of $50 \%$ since there is no published study on the prevalence of suicidal thought in DM patients in Ethiopia and Africa, 5\% margin of error, 95\% confidence level and $10 \%$ non-response rate. Sampling interval (K) was calculated by dividing the number of diabetic patients with follow up per month (1384) to the sample size (423) and $\mathrm{K}$ was found to be 3 . The first study participant was selected from three of the participants attending follow up visits by a lottery method then every third of respondents in the waiting room at the diabetic outpatient unit of Felegehiwot referral hospital were included to sample by using systematic random sampling.

\subsection{Variable}

Presence or absence of suicidal thought was the dependent variable whereas socio-demographic variables, clinical and illness-related factors (duration of illness, treatment regimen, glycemic control, medication adherence, Diabetes type, Diabetes complications, body mass index (BMI), comorbid medical illness, and comorbid depression), psychosocial factors and substance use variables were the independent variables.

\subsection{Operational Definitions}

Suicidal thought: is defined as if the respondent answers the question have you ever thought of killing yourself? If the answer is yes, the respondent has suicidal thoughts [30].

Depression: Score $\geq 5$ on patient health questionnaire-9 depression scale [31].

Adherence to medication: low-adherence if the score is $<6$, medium adherence if the score is 6 and 7, and high adherence if the score is 8 on 8 -Item Morisky medication adherence scale [32-35].

Comorbid medical illness: The presence of other diagnosed medical disorders in addition to diabetes mellitus.

Social support: individuals who scored $\geq 9$ (moderate and strong) on the Oslo 3-item social support scale [36].

Glycemic control: Glycemic control was assessed using a fasting blood glucose level of the previous visit from the medical chart of patients. Reading $\leq 130 \mathrm{mg} / \mathrm{dl}$ was considered 
as good control and FBG level $>130 \mathrm{mg} / \mathrm{dl}$ was considered as a poor control [37].

Current substance use: use of at least one of the specified substance within the last 3 months [38].

Moderate physical activity: was defined as routine walking at least five times per week for at least $30 \mathrm{~min}$ at a time or engaging during the survey period in regular moderate (at least five times per week for at least $30 \mathrm{~min}$ at a time) by the American College of Sports Medicine Guidelines [39].

\subsection{Data Collection Procedure and Instruments}

The English version of the questionnaire was translated to the Amharic language by experts and it was reviewed by psychiatry professionals and pretested on a sample of $21(5 \%)$ of sample size on diabetic patients at Addisalem hospital, which is 5 kilometers far from the study setting. Data were collected by four BSc psychiatry nurses and supervised by two MSc in mental health professional after three days of training was given for data collectors and supervisors. WHO's composite international diagnostic interview (CIDI) suicide manual has been adapted to assess suicidal thoughts among patients with diabetes mellitus. Suicidal thought: "Have you ever thought of killing yourself? CIDI was used in a different institution-based study in Ethiopia [40-42].

Depression has assessed with Patient Health Questionnaire-9; a nine-item self-report instrument that has been validated in the general hospital setting in Ethiopia [31]. Medication adherence was assessed using the 8-item Morisky medication adherence scale which is the latest version of the scale and has a good internal consistency, Cronbach $\alpha=0.83$ [43]. The Oslo-3-item social support scale was used to assess the social support of participants [36]. Socio-demographic, substance-related, and clinical variables not mentioned above were assessed by developing a questionnaire from different published literature.

\subsection{Data Processing and Analysis}

Data was entered into Epi-info version 7 and analyzed using SPSS version 20. Descriptive statistics (frequency, mean, median, standard deviation, percentages, and crosstabs) were used to summarize the outcome and independent variables. The association between suicidal thought and explanatory variables was investigated using binary logistic regression. All independent variables with $p$-value $<0.25$ in bivariate logistic regression were fitted into a multivariate logistic regression model to control the effect of confounders and identify factors associated with suicidal thought. The strength of the association between suicidal thought and factors interpreted using ORs with 95\% CI and P-value $<0.05$ was considered statistically significant.

\section{Results}

\subsection{Socio-demographic Characteristics of the Participants}

From 423 participants intended to be included in this study, complete data was obtained from 421, making the response rate of this study to be $99.5 \%$. More than half of the respondents were males $227(53.9 \%)$. The mean age $( \pm \mathrm{SD})$ of the respondents was $38.0(( \pm 13.9)$ years and it ranges from 18 to 76 years. Among respondents, $353(83.6 \%)$ were orthodox Christian in religion $256(60.8 \%)$ were married. About 192 $(45.6 \%)$ of respondents didn't have the education and 196 $(46.6 \%)$ of respondents were farmers. The median $( \pm \mathrm{IQR})$ value of reported monthly income of the respondents was 900 $( \pm 1350)$ ETB with a range of 450 to 20,000 ETB (Table 1$)$.

Table 1. Descriptions of Socio demographic characteristics among patients with diabetes mellitus on follow up at Felegehiwot referral hospital $(n=421)$, Bahirdar, Ethiopia, 2017.

\begin{tabular}{|c|c|c|}
\hline Variable & Frequency & Percentage \\
\hline \multicolumn{3}{|l|}{ Age group } \\
\hline $18-24$ & 74 & 17.6 \\
\hline $25-34$ & 116 & 27.6 \\
\hline $35-44$ & 97 & 23 \\
\hline $45-54$ & 77 & 18.3 \\
\hline$\geq 55$ & 57 & 13.5 \\
\hline \multicolumn{3}{|l|}{ Sex } \\
\hline Male & 227 & 53.9 \\
\hline Female & 194 & 46.1 \\
\hline \multicolumn{3}{|l|}{ Marital status } \\
\hline Married & 256 & 60.8 \\
\hline Single & 93 & 22.5 \\
\hline Widowed/divorced & 72 & 16.7 \\
\hline \multicolumn{3}{|l|}{ Religion } \\
\hline Orthodox & 352 & 83.6 \\
\hline Muslim & 51 & 12.1 \\
\hline Protestant & 18 & 4.3 \\
\hline \multicolumn{3}{|l|}{ Occupation } \\
\hline Government employee & 71 & 16.9 \\
\hline Private employee & 58 & 13.8 \\
\hline Unemployed & 28 & 6.7 \\
\hline Farmer & 196 & 46.6 \\
\hline Student & 26 & 6.2 \\
\hline Others & 42 & 10 \\
\hline \multicolumn{3}{|l|}{ Educational status } \\
\hline Non educated & 192 & 45.6 \\
\hline Grade1-8 & 93 & 22.1 \\
\hline Grade9-12 & 58 & 13.8 \\
\hline Diploma and above & 78 & 18.5 \\
\hline \multicolumn{3}{|l|}{ Monthly income } \\
\hline$<735$ & 159 & 37.8 \\
\hline $735-1176$ & 96 & 22.8 \\
\hline$>1176$ & 166 & 39.4 \\
\hline \multicolumn{3}{|c|}{ With whom patient is living } \\
\hline With family & 375 & 89 \\
\hline Alone & 46 & 11 \\
\hline \multicolumn{3}{|l|}{ Social support } \\
\hline Poor & 242 & 57.5 \\
\hline Moderate & 128 & 30.4 \\
\hline Strong & 51 & 12.1 \\
\hline
\end{tabular}

\subsection{Clinical and Illness-related Characteristics of the Respondents}

About $184(43.7 \%)$ of participants were on the injectable form (insulin), $57(13.5 \%)$ were on combined oral hypoglycemic and insulin treatment regimen, and: the rest $180(42.8 \%)$ were on oral hypoglycemic agents. More than half of the study participants 257 (61\%) had been living with diabetes for less than 5 years, the rest $164(39 \%)$ had been 
diagnosed for the illness before five years.

Concerning comorbidity, 56 (13.3\%) of participants had a comorbid medical illness, of which hypertension was the commonest one, $44(78.6 \%)$. Only $18(4.3 \%)$ of the study participants had complications of illness diagnosed by a medical practitioner with evidence from a medical chart of patients. Regarding adherence to anti-diabetic medication 85 (20.2\%), 167 (39.7\%) and 169 (40.1\%) of participants had low, intermediate, and high adherence respectively. About 205 (48.7\%) of respondents had a fluctuation of their blood glucose level beyond the normal values as measured by fasting blood sugar in the previous visit. The prevalence of comorbid depression in the study was found to be $38.7 \%$ (Table 2).

Table 2. Clinical characteristics of diabetic patients attending Felegehiwot referral Hospital, Diabetic Clinic ( $n=421)$, Bahirdar, Northwest Ethiopia, July 2017.

\begin{tabular}{|c|c|c|}
\hline Variable & Frequency & Percentage \\
\hline \multicolumn{3}{|l|}{ Type of DM } \\
\hline Type1 & 58 & 13.8 \\
\hline Type 2 & 363 & 86.2 \\
\hline \multicolumn{3}{|l|}{ Duration since DM dx } \\
\hline$<5$ years & 257 & 61 \\
\hline$>=5$ years & 164 & 39 \\
\hline \multicolumn{3}{|l|}{ Current DM treatment } \\
\hline Insulin & 184 & 43.7 \\
\hline Insulin and oral agents & 57 & 13.6 \\
\hline Oral hypoglycemic agents & 180 & 42.8 \\
\hline \multicolumn{3}{|l|}{ Co morbid medical illness } \\
\hline Yes & 56 & 13.3 \\
\hline No & 365 & 86.7 \\
\hline \multicolumn{3}{|c|}{ Type of co morbid medical illness } \\
\hline HTN & 44 & 78.57 \\
\hline HIV & 6 & 10.63 \\
\hline Asthma & 3 & 5.4 \\
\hline Renal diseases & 3 & 5.4 \\
\hline \multicolumn{3}{|l|}{ Complication due to DM } \\
\hline Yes & 18 & 4.3 \\
\hline No & 401 & 5.2 \\
\hline \multicolumn{3}{|l|}{ Glycemic control } \\
\hline Poor & 205 & 48.7 \\
\hline Good & 216 & 51.3 \\
\hline \multicolumn{3}{|l|}{ Medication adherence } \\
\hline low & 85 & 20.2 \\
\hline Medium & 167 & 39.7 \\
\hline High & 169 & 40.1 \\
\hline Moderate physical activity & 129 & 30.6 \\
\hline Yes & 292 & 69.4 \\
\hline \multicolumn{3}{|l|}{ No } \\
\hline \multicolumn{3}{|l|}{ Co morbid depression } \\
\hline Yes & 163 & 38.7 \\
\hline No & 258 & 61.3 \\
\hline \multicolumn{3}{|l|}{ Body mass index (kg/m2) } \\
\hline$<18.5$ & 40 & 9.5 \\
\hline $18.5-24.9$ & 333 & 79.1 \\
\hline$\geq 25.00$ & 48 & 11.4 \\
\hline \multicolumn{3}{|c|}{ Family history of suicidal attempt } \\
\hline Yes & 15 & 3.6 \\
\hline No & 406 & 96.4 \\
\hline
\end{tabular}

\subsection{Substance Use Characteristics of Respondents}

About $136(32.3 \%)$ of the respondents had a history of substance use within the past three months before data collection time. Among these; the majority, 123 (90.5\%) reported that they were using alcohol and $11(8 \%)$ of them were smoking a cigarette, but only two of the respondents $(1.5 \%)$ had used chat within the past three months (Table 3).

Table 3. Substance use characteristics of study participants at Felegehiwot Referral Hospital, Bahir Dar, Northwest Ethiopia, July 2017 (n=421).

\begin{tabular}{lll}
\hline Variables & Frequency & Percentages \\
\hline Ever use of substance & & \\
Yes & 209 & 49.6 \\
No & 212 & 50.4 \\
Ever use of alcohol & & \\
Yes & 193 & 45.8 \\
No & 228 & 54.2 \\
Ever cigarette smoking & & \\
Yes & 12 & 2.85 \\
No & 409 & 97.15 \\
Ever chat chewing & & \\
Yes & 3 & 7.1 \\
No & 418 & 92.9 \\
Current substance use & & \\
Yes & 136 & 32.3 \\
No & 285 & 67.7 \\
Current alcohol use & & \\
Yes & 123 & 29.2 \\
No & 298 & 70.8 \\
Current cigarette smoking & & \\
Yes & 11 & 2.6 \\
No & 410 & 97.4 \\
Current chat chewing & & \\
Yes & 2 & 0.5 \\
No & 419 & 99.5 \\
\hline
\end{tabular}

\subsection{Prevalence of Suicidal Thoughts Among Patients with Diabetes Mellitus in North-west Ethiopia}

Eighty- three (19.7\%) of the respondents had reported a history of suicidal thought in their lifetime (Figure 1). The proportion of suicidal thought by sex showed that $44(53 \%)$ were male and $39(47 \%)$ female. From those who have suicidal thoughts $28(33.7 \%)$ were also suicidal in the past year (Table 4). The cross-tabulation of suicidal thought across categories of diabetes type shows that about $21(36 \%)$ of type $1 \mathrm{DM}$ and $62(17 \%)$ of type $2 \mathrm{DM}$ patients had a suicidal thought in their lifetime.

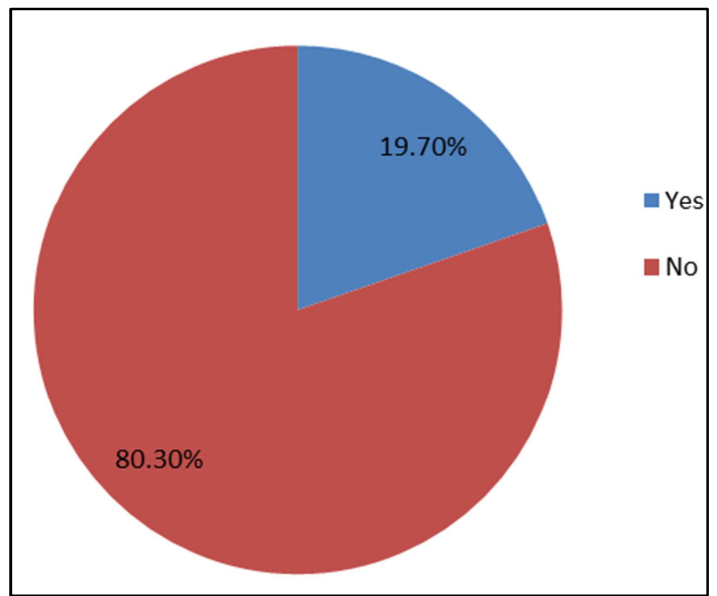

Figure 1. Prevalence of suicidal thought among patients with diabetes mellitus on follow up at Felegehiwot referral hospital $(n=421)$, Bahirdar, Ethiopia, 2017. 
Table 4. Frequency distribution of suicidal ideation among diabetes mellitus patients at outpatient department of Felegehiwot Referral Hospital, Bahirdar, Ethiopia, July 2017 ( $n=421)$.

\begin{tabular}{|c|c|c|}
\hline Variable & Frequency & Percentage \\
\hline \multicolumn{3}{|l|}{ Ever suicidal ideation } \\
\hline Yes & 83 & 19.7 \\
\hline No & 338 & 80.3 \\
\hline Duration of suicidal ideation & 28 & 33.7 \\
\hline$\leq 12$ months & 55 & 66.3 \\
\hline \multicolumn{3}{|l|}{$>12$ months } \\
\hline \multicolumn{3}{|l|}{ Suicidal ideation in DM types } \\
\hline Type 1 DM & 21 & 25.3 \\
\hline Type 2 DM & 62 & 74.7 \\
\hline \multicolumn{3}{|l|}{ Suicidal ideation 1 month } \\
\hline Yes & 7 & 1.7 \\
\hline No & 417 & 98.3 \\
\hline \multicolumn{3}{|l|}{ Ever plan of suicide } \\
\hline Yes & 45 & 10.7 \\
\hline No & 376 & 89.3 \\
\hline \multicolumn{3}{|l|}{ Ever suicidal attempt } \\
\hline Yes & 32 & 7.6 \\
\hline No & 389 & 92.4 \\
\hline \multicolumn{3}{|l|}{ Ever suicidal attempt } \\
\hline Type1 & 8 & 25 \\
\hline Type 2 & 24 & 75 \\
\hline \multicolumn{3}{|l|}{ Duration of suicidal attempt } \\
\hline$\leq 12$ months & 12 & 36.4 \\
\hline$>12$ months & 20 & 63.6 \\
\hline \multicolumn{3}{|l|}{ Frequency of suicidal attempt } \\
\hline Once & 25 & 78.1 \\
\hline Two times & 5 & 15.6 \\
\hline More than two times & 2 & 6.3 \\
\hline \multicolumn{3}{|l|}{ Reasons for suicidal attempt } \\
\hline Family conflict & 6 & 18.75 \\
\hline Economic problem & 6 & 18.75 \\
\hline Death in family & 2 & 6.25 \\
\hline Related to DM & 12 & 37.5 \\
\hline Others & 6 & 18.75 \\
\hline \multicolumn{3}{|l|}{ Methods of attempt } \\
\hline Hanging & 15 & 46.89 \\
\hline Poisoning & 13 & 40.61 \\
\hline Sharp tools & 2 & 6.25 \\
\hline Insulin overdose & 2 & 6.25 \\
\hline
\end{tabular}

\subsection{Factors Associated with Lifetime Suicidal Thought Among People with Diabetes Mellitus}

In bivariate analysis socio-demographic variables; marital status, occupation, living arrangement, income and clinical variables such as type of diabetes, Current diabetes treatment regimen, medication adherence, the presence of comorbid medical illness, comorbid depression, family history of suicidal attempt and family history of suicide were found to have a p-value $<0.25$. These variables were fitted into a multivariate binary logistic regression model to control the effect of confounders.

In the multivariable regression analysis of factors for suicidal thought, the model adequately fits the data as the pvalue from Hosmer and Lemeshow test was 0.906 and only marital status, unemployment, type of DM, comorbid depression and comorbid medical illness were found to be factors associated with suicidal thought.

The odds of having suicidal thought among respondents who are divorced/widowed was 2.4 times higher as compared to married study participants $(\mathrm{AOR}=2.38,95 \% \mathrm{CI}$ : 1.12 $5.02)$. In this study, a type 1 diabetic patient was 2.6 times more likely to have suicidal thoughts than type 2 diabetic patients (AOR=2.56, 95\% CI: 1.16-5.73). Comorbid medical illness was found to be a significant factor for suicidal thoughts. The odds of having suicidal thought among participants with comorbid medical illness was 4.7 times higher as compared to those without comorbid medical illness $(\mathrm{AOR}=4.74,95 \% \mathrm{CI}: 2.26-9.93)$. The presence of comorbid depression was also another factor for suicidal thoughts. Patients with comorbid depression were about two times more likely to have suicidal thoughts compared to those who have no depression $(\mathrm{AOR}=1.92$, 95\% CI: 1.09 3.38) (Table 5).

Table 5. Bivariate and multivariable Logistic Regression analysis showing the Associations between some of the factors and suicidal ideation among Diabetic patients at Felegehiwot Referral Hospital, Bahir Dar, Ethiopia, 2017 (n=421).

\begin{tabular}{|c|c|c|c|c|}
\hline \multirow{2}{*}{ Explanatory variable } & \multicolumn{2}{|c|}{ Suicidl ideatin } & \multirow{2}{*}{$\operatorname{COR}(95 \% \mathrm{CI})$} & \multirow{2}{*}{$\operatorname{AOR}(95 \%$ CI) } \\
\hline & Yes & No & & \\
\hline \multicolumn{5}{|l|}{ Marital status } \\
\hline Married & 35 & 221 & 1.00 & 1.00 \\
\hline Single & 21 & 72 & $1.84(1.01,3.36)$ & $0.90(0.34,2.08)$ \\
\hline Divorced/widowed & 27 & 45 & $3.79(2.09,6.87)$ & $2.38(1.12,5.02)^{*}$ \\
\hline \multicolumn{5}{|l|}{ Occupation status } \\
\hline Employed* & 23 & 106 & 1.00 & 1.00 \\
\hline Farmer & 35 & 161 & $1.00(0.56,1.79)$ & $1.07(0.47,2.40)$ \\
\hline Student & 9 & 17 & $2.44(0.97,6.16)$ & $2.54(0.67,9.62)$ \\
\hline Others* & 5 & 37 & $0.62(0.22,1.76)$ & $0.44(0.12,1.67)$ \\
\hline \multicolumn{5}{|c|}{ With whom patient is living } \\
\hline Family & 64 & 311 & 1.00 & 1.00 \\
\hline Alone & 19 & 27 & $3.42(1.79,6.52)$ & $1.60(0.68,3.72)$ \\
\hline \multicolumn{5}{|l|}{ Type of DM } \\
\hline Type 2 & 62 & 301 & 1.00 & 1.00 \\
\hline \multicolumn{5}{|c|}{ Current DM treatment type } \\
\hline Insulin & 34 & 150 & $1.05(0.62,1.79)$ & $0.89(0.45,1.78)$ \\
\hline Insulin and oral agents & 17 & 40 & $1.97(0.99,3.89)$ & $2.46(0.910,5.53)$ \\
\hline
\end{tabular}




\begin{tabular}{lllll}
\hline \multirow{2}{*}{ Explanatory variable } & Suicidl ideatin & & \multirow{2}{*}{ COR (95\% CI) } & \multirow{2}{*}{ AOR (95\% CI) } \\
\cline { 2 - 4 } & Yes & No & 1.00 & 1.00 \\
\hline Oral agents only & 32 & 148 & $5.12(2.83,9.33)$ & $4.74(2.26,9.93)^{* *}$ \\
Comorbid illness & & & 1.00 & 1.00 \\
Yes & 27 & 306 & & $1.92(1.09,3.38)^{*}$ \\
No & 56 & 119 & $2.07(1.28,3.37)$ & 1.00 \\
Depression & 44 & 219 & 1.00 & \\
Yes & 39 & & & \\
No & & &
\end{tabular}

$*$ P-value $<0.05$.

$* * \mathrm{P}$-value $<0.01$.

Model chi-square $=3.412, \mathrm{df}=8$ and $\mathrm{sig}=0.906$.

*Employed are both Government and Private employed.

*Others are merchants and housewife.

\section{Discussion}

The present study is the first of its kind that assessed suicidal thought among people with diabetes mellitus in Ethiopia. The lifetime occurrence of suicidal thoughts was found to be $19.7 \%$ with a $95 \%$ confidence interval of (16.20, 23.00). This prevalence of suicidal thought was in line with a study in Jordan which is $20 \%$ [8].

On the contrary, the finding was lower than the findings from an institution based cross-sectional study conducted at wake forest university, South Carolina, the USA which is $26.4 \%$ [22] and 51.4\% in South Korea [44]. It was also lower than from the result of a study conducted in Pittsburg hospital; USA among youths with IDDM, which is $58.5 \%$ [23]. On the other hand, it is higher than a study conducted in New York, USA 9\% [24], Canada 15\% [25], and Australia 14\% [26].

These differences might be due to the socio-cultural difference in which suicidal behaviors are stigmatized in our society and under-reporting might occur. It might also be due to the sample size used in the USA study is smaller than the current study. An additional explanation for this difference might be the age of participants in USA study is younger than the current study that may increase the prevalence of suicidal thought and variation in study design could also account for the discrepancy (prospective cohort study in the USA) and interview schedule for children was the tool in one of the USA studies. In addition to this, some of the risk factors for suicidal thoughts were older age, longer duration of diabetes mellitus, medication non-adherence, and substance use in previous studies, but not risk factors in our study so might bring the difference.

The odds of suicidal thought among participants who were divorced/widowed was 2.4 times higher as compared to married participants. This is consistent with findings from studies in Korea [44] and community [42] and institutionbased studies in Ethiopia [40]. Loss of marital relationships is a major stressful life event and might disrupt social and emotional functioning which will expose to suicidal thoughts.

Participants with comorbid medical illnesses were 4.7 times more likely to have suicidal thoughts than those without comorbid medical illnesses. This is supported by studies conducted in Jordan [8], South Korea [44], Brazil [45] and the USA [46]. Reasons may be due to chronic intractable pain secondary to a comorbid medical illness, pill burdens, disruption of relationships, and loss of occupational status that may predispose the individual to socioeconomic difficulties and stress. The depressive effect of antihypertensive drugs might further increase suicidal thoughts.

The odds of suicidal thoughts among participants with comorbid depression were 1.92 times higher as compared to those who had no depression. This is supported by a study in the USA [27]. The possible reason may be depression will lead to a decrease in serotonin levels. Studies have shown an association between serotonin decrease and suicidal behavior $[9,47]$. It may also be due to the direct impact of depression on patients which makes them socially withdrawn, hopeless and worthless, feeling guilty.

In this study type 1 , diabetic patients were 2.6 times more likely to have suicidal thoughts than type 2 diabetic patients. This is supported by another study in the USA [48]. This might have been associated with the genetic basis of the illness and the age of participants younger in type $1 \mathrm{DM}$. It might also be due to the chronicity of the illness and suicidal effect of exogenous insulin administration in type 1 DM. Since the study was an institution based cross-sectional, it is difficult to know causal interpretations between suicidal thought and explanatory variables. Recall bias might also be the limitation of this study. Social desirability bias is also a potential limitation since suicidal thought is stigmatized by most society especially in developing countries like Ethiopia.

\section{Conclusion}

Suicidal thought was high in DM patients with follow up. This suggests that suicidal thought is important public health problem. There are various factors associated with this high prevalence of suicidal thoughts in this study. These include being widowed and divorced, unemployment, the presence of comorbid medical illness, comorbid depression, and having a clinical diagnosis of type 1 DM. Early management of medical comorbidities, depression, and psychosocial problems should be given due attention.

\section{Abbreviations}

BMI: Body mass index, CIDI: Composite international 
diagnostic interview, DM: Diabetes mellitus, IDDM: Insulindependent diabetes mellitus, NIDDM: Non-insulindependent diabetes mellitus, OR: Odds ratio, PHQ-9: Patient health questionnaire-9, SPSS: Statistical package for social science, UOG: University of Gondar, USA: United States of America, WHO: World health organization.

\section{Declarations}

\section{Ethics Approval and Consent to Participate}

All processes followed were per the ethical principles after ethical approval was received from the responsible committee of the institutional review board of the University of Gondar. Verbal informed consent was obtained from all study participants since participation in the study pose no more than a minimal risk to the participants and this was also approved by the ethical committee of the above institution. Because the participation of patients in this study was entirely voluntary, confidential, and private information like name, image, video, and address were protected and ethics committee approved this procedure.

\section{Consent for Publication}

Not applicable.

\section{Availability of Data and Materials}

The authors approve that all data underlying the findings are completely accessible without limitation and also pertinent data are included in the manuscript.

\section{Competing Interests}

The authors announce that as we have no competing interests.

\section{Authors' Contributions}

$\mathrm{MN}$ and $\mathrm{MB}$ contributed to the design, conduct, and analyzing the research and in the manuscript preparation. $\mathrm{AB}$ contributed to the review of the manuscript. All authors read and approved the manuscript.

\section{Acknowledgements}

First I would like to express my deepest gratitude to the University of Gondar College of medicine and health science \& Felegehiwot Specialized hospital for all financial support provided. My thanks go to data collectors, supervisors, and participants of this study for devoting their precious time and genuine cooperation they show.

\section{References}

[1] Organization WH. mhGAP: Mental Health Gap Action Programme: scaling up care for mental, neurological, and substance use disorders. 2008.
[2] Organization WH. Preventing suicide: a global imperative: World Health Organization; 2014.

[3] Borges G, Nock MK, Haro Abad JM, Hwang I, Sampson NA, Alonso J, et al. Twelve-month prevalence of and risk factors for suicide attempts in the World Health Organization World Mental Health Surveys. J Clin Psychiatry. 2010; 71 (12): 1617-28. Epub 2010/09/08.

[4] Nock MK, Banaji MR. Prediction of suicide ideation and attempts among adolescents using a brief performance-based test. Journal of consulting and clinical psychology. 2007; 75 (5): 707-15. Epub 2007/10/03.

[5] Sadock BJ, Sadock VA. Kaplan and Sadock's synopsis of psychiatry: Behavioral sciences/clinical psychiatry: Lippincott Williams \& Wilkins; 2011.

[6] Lee H-Y, Hahm M-I, Lee SG. The risk of suicidal thoughts in diabetes varies by diabetes regimen, diabetes duration, and HbA1c level. Journal of psychosomatic research. 2014; 76 (4): 275-9.

[7] Mościcki EK. Epidemiology of suicidal behavior. Suicide and life-threatening behavior. 1995; 25 (1): 22-35.

[8] Amer NRY, Hamdan-Mansour AM. Psychosocial predictors of suicidal thoughts in patients diagnosed with chronic illnesses in Jordan. Issues in mental health nursing. 2014; 35 (11): 864-71.

[9] Masango S, Rataemane S, Motojesi A. Suicide and suicide risk factors: A literature review. South African Family Practice. 2008; 50 (6): 25-9.

[10] Veisani Y, Mohamadian F. Prevalence and comorbidity of common mental disorders and associations with suicidal thoughts in the adult population. 2017; 39: e2017031.

[11] Giletta M, Calhoun CD, Hastings PD, Rudolph KD, Nock MK, Prinstein MJ. Multi-Level Risk Factors for Suicidal thought Among at-Risk Adolescent Females: The Role of Hypothalamic-Pituitary-Adrenal Axis Responses to Stress. Journal of abnormal child psychology. 2015; 43 (5): 807-20. Epub 2014/06/25.

[12] Ongeri L, McCulloch CE, Neylan TC, Bukusi E, Macfarlane $\mathrm{SB}$, Othieno C, et al. Suicidality and associated risk factors in outpatients attending a general medical facility in rural Kenya. J Affect Disord. 2018; 225: 413-21. Epub 2017/08/30.

[13] Na PJ, Kim KB, Lee-Tauler SY, Han HR, Kim MT, Lee HB. Predictors of suicidal thoughts in Korean American older adults: analysis of the Memory and Aging Study of Koreans (MASK). International journal of geriatric psychiatry. 2017; 32 (12) 1272-9. Epub 2016/10/26.

[14] Depp CA, Moore RC, Perivoliotis D, Holden JL, Swendsen J, Granholm EL. Social behavior, interaction appraisals, and suicidal thought in schizophrenia: The dangers of being alone. Schizophrenia research. 2016; 172 (1-3): 195-200. Epub 2016/03/08.

[15] Inder KJ, Handley TE, Johnston A, Weaver N, Coleman C, Lewin TJ, et al. Determinants of suicidal thought and suicide attempts: parallel cross-sectional analyses examining geographical location. BMC Psychiatry. 2014; 14: 208. Epub 2014/07/24

[16] Arsenault-Lapierre G, Kim C, Turecki G. Psychiatric diagnoses in 3275 suicides: a meta-analysis. BMC Psychiatry. 2004; 4: 37. Epub 2004/11/06. 
[17] Agrawal A, Tillman R, Grucza RA, Nelson EC, McCutcheon VV, Few L, et al. Reciprocal relationships between substance use and disorders and suicidal thought and suicide attempts in the Collaborative Study of the Genetics of Alcoholism. J Affect Disord. 2017; 213: 96-104. Epub 2017/02/19.

[18] Abstracts from the 2017 Society of General Internal Medicine Annual Meeting. J Gen Intern Med. 2017; 32 (Suppl 2): 83808. Epub 2017/04/12.

[19] Ali S, Stone M, Peters J, Davies M, Khunti K. The prevalence of co-morbid depression in adults with Type 2 diabetes: a systematic review and meta-analysis. Diabetic Medicine. 2006; 23 (11): 1165-73.

[20] Barnard K, Skinner T, Peveler R. The prevalence of co-morbid depression in adults with Type 1 diabetes: a systematic literature review. Diabetic Medicine. 2006; 23 (4): 445-8.

[21] Pouwer F, Nefs G, Nouwen A. Adverse effects of depression on glycemic control and health outcomes in people with diabetes: a review. Endocrinology and metabolism clinics of North America. 2013; 42 (3): 529-44.

[22] Goldston DB, Kelley AE, Reboussin DM, Daniel SS, Smith JA, Schwartz RP, et al. Suicidal thought and behavior and noncompliance with the medical regimen among diabetic adolescents. Journal of the American Academy of Child \& Adolescent Psychiatry. 1997; 36 (11): 1528-36.

[23] Goldston DB, Kovacs M, Ho VY, Parrone PL, Stiffler L. Suicidal thought and suicide attempts among youth with insulindependent diabetes mellitus. Journal of the American Academy of Child \& Adolescent Psychiatry. 1994; 33 (2): 240-6.

[24] Olfson M, Weissman MM, Leon AC, Sheehan DV, Farber L. Suicidal thought in primary care. Journal of General Internal Medicine. 1996; 11 (8): 447-53.

[25] Fuller-Thomson E, Sawyer J-L. The lifetime prevalence of suicidal thoughts in a representative sample of Canadians with type 1 diabetes. Diabetes research and clinical practice. 2009; 83 (1): e9-e11.

[26] Handley T, Ventura A, Browne J, Rich J, Attia J, Reddy P, et al. Suicidal thought reported by adults with Type 1 or Type 2 diabetes: results from Diabetes MILES-Australia. Diabetic medicine. 2015.

[27] Roy A, Roy M, Janal M. Suicide attempts and ideation in African-American type 1 diabetic patients. Psychiatry research 2010; 179 (1): 53-6.

[28] Ceretta LB, Réus GZ, Abelaira HM, Jornada LK, Schwalm MT, Hoepers NJ, et al. Increased prevalence of mood disorders and suicidal thought in type 2 diabetic patients. Acta Diabetologia. 2012; 49 (1): 227-34.

[29] Belayneh M. Inpatient satisfaction and associated factors towards nursing care at Felegehiwot Referral Hospital, Amhara Regional State, Northwest Ethiopia.

[30] Kessler RC, Üstün TB. The world mental health (WMH) survey initiative version of the world health organization (WHO) composite international diagnostic interview (CIDI). International journal of methods in psychiatric research. 2004; 13 (2): 93-121.

[31] Gelaye B, Williams MA, Lemma S, Deyessa N, Bahretibeb Y, Shibre T, et al. Validity of the patient health questionnaire-9 for depression screening and diagnosis in East Africa.
Psychiatry research. 2013; 210 (2): 653-61.

[32] Al-Qazaz HK, Hassali MA, Shafie AA, Sulaiman SA, Sundram S, Morisky DE. The eight-item Morisky Medication Adherence Scale MMAS: translation and validation of the Malaysian version. Diabetes research and clinical practice. 2010; 90 (2): 216-21.

[33] Abebe SM, Berhane Y, Worku A. Barriers to diabetes medication adherence in North West Ethiopia. SpringerPlus. 2014; 3 (1): 195.

[34] Abebe SM, Berhane Y, Worku A, Alemu S, Mesfin N. Level of sustained glycemic control and associated factors among patients with diabetes mellitus in Ethiopia: a hospital-based cross-sectional study. Diabetes, metabolic syndrome, and obesity: targets and therapy. 2015; 8: 65 .

[35] de Oliveira-Filho AD, Morisky DE, Neves SJF, Costa FA, de Lyra DP. The 8-item Morisky Medication Adherence Scale: validation of a Brazilian-Portuguese version in hypertensive adults. Research in Social and Administrative Pharmacy. 2014; 10 (3): 554-61.

[36] Abiola T, Udofia O, Zakari M. Psychometric properties of the 3-item Oslo social support scale among clinical students of Bayero University Kano, Nigeria. Malaysian Journal of Psychiatry. 2013; 22 (2): 32-41.

[37] Tekla G, Hussien J, Tesfaye D. Non-adherence and associated factors among type 2 diabetic patients at Jimma University Specialized Hospital, Southwest Ethiopia. Journal of Medical Sciences. 2013; 13 (7): 578 .

[38] Humeniuk R, Ali R, Babor TF, Farrell M, Formigoni ML, Jittiwutikarn J, et al. Validation of the alcohol, smoking, and substance involvement screening test (ASSIST). Addiction. 2008; 103 (6): 1039-47.

[39] Haskell WL, Lee I-M, Pate RR, Powell KE, Blair SN, Franklin BA, et al. Physical activity and public health. Updated recommendation for adults from the American College of Sports Medicine and the American Heart Association. Circulation. 2007.

[40] Bitew H, Andargie G, Tadesse A, Belete A, Fekadu W, Mekonen T. Suicidal thought, Attempt, and Determining Factors among HIV/AIDS Patients, Ethiopia. Depression research and treatment. 2016.

[41] Hussien ZN, Solomon H, Yohannis Z, Ahmed AM. Prevalence and Associated Factors of Suicidal thought and Attempt among People with Schizophrenia at Amanuel Mental Specialized Hospital Addis Ababa, Ethiopia. Journal of Psychiatry: Open Access. 2014; 2015.

[42] Fekadu A, Medhin G, Selamu M, Shiferaw T, Hailemariam M, Rathod SD, et al. Non-fatal suicidal behavior in rural Ethiopia: a cross-sectional facility-and population-based study. BMC psychiatry. 2016; 16 (1): 75.

[43] Morisky DE, Ang A, Krousel-Wood M, Ward HJ. Predictive validity of a medication adherence measure in an outpatient setting. The Journal of Clinical Hypertension. 2008; 10 (5): 348-54.

[44] Han SJ, Kim HJ, Choi YJ, Lee KW, Kim DJ. Increased risk of suicidal thoughts in Korean adults with both diabetes and depression. Diabetes research and clinical practice. 2013; 101 (3): e14-e7. 
[45] de Ornelas Maia ACC, de Azevedo Braga A, Brouwers A, Nardi AE, e Silva ACdO. Prevalence of psychiatric disorders in patients with diabetes types 1 and 2. Comprehensive psychiatry. 2012; 53 (8): 1169-73.

[46] Goodwin RD, Marusic A, Hoven CW. Suicide attempts in the United States: the role of physical illness. Social science \& medicine. 2003; 56 (8): 1783-8.
[47] Apter A. Suicide and suicidal behavior. Public health reviews. 2012; 34 (2): 1.

[48] Pompili M, Lester D, Innamorati M, De Pisa E, Amore M, Ferrara C, et al. Quality of life and suicide risk in patients with diabetes mellitus. Psychosomatics. 2009; 50 (1): 16-23. 